\title{
Oxygen isotope disequilibrium in the juvenile portion of oyster shells biases seawater temperature reconstructions
}

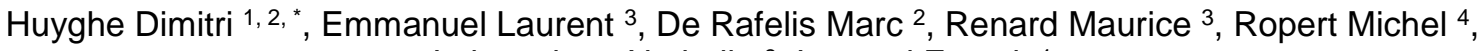 \\ Labourdette Nathalie ${ }^{3}$, Lartaud Franck ${ }^{1}$
}

1 Sorbonne Université, CNRS, Laboratoire d'Ecogéochimie des Environnements Benthiques, LECOB, F-66650, Banyuls-sur-mer, France

${ }^{2}$ Géosciences Environnement Toulouse, CNRS, IRD, Université Paul Sabatier Toulouse 3, 14 Avenue

Edouard Belin, 31400, Toulouse, France

${ }^{3}$ Sorbonne Université, CNRS-INSU, Institut des Sciences de la Terre Paris, ISTeP, F-75005 Paris,

France

${ }^{4}$ Ifremer, Laboratoire Environnement Ressource de Normandie, Avenue du Général de Gaulle, BP 32 ,

14520, Port-en-Bessin, France

* Corresponding author : Dimitri Huyghe, email address : damien.huyghe@mines-paristech.fr

\begin{abstract}
:
For decades, bivalve shells have constituted one of the most common supports for paleoclimatic archives based on stable isotope approaches. In this work, we conducted chemical marking and recapture techniques to study the fluctuation of $\delta 180$ values of oyster shells of the species Magallana gigas reared in natural environment in Normandy (France) for two years. The results were compared to the continuous monitoring of temperature and salinity and monthly records of seawater $\delta 180$. Isotopic measurements were performed on the hinge area that regroups the whole life of the oysters. Here we demonstrate that oysters mineralized their shells with no significant growth breaks during the two-years experiment, even at temperatures below $6{ }^{\circ} \mathrm{C}$. The results confirm that adult oysters (i.e. $>1 \mathrm{yr}$ ) mineralized their shells at equilibrium. However, juvenile specimens exhibit a strong isotopic disequilibrium, with a maximum shift of the $\delta 180$ values of $3 \%$ in winter, likely due to kinetic isotope effects. This corresponds to a reconstructed temperature up to $13^{\circ} \mathrm{C}$ warmer than expected. This work indicates that although these oyster shells can be used as an accurate archive of (paleo)environmental conditions, the shell portion mineralized during the juvenile stage (i.e. $<1 \mathrm{yr}$ ) should be avoided for paleotemperature reconstructions. Given the wide use of bivalve shells as environmental archives, similar studies on others species are required.
\end{abstract}

\section{Highlights}

We analyze the $\delta^{18} \mathrm{O}$ composition of oyster shells of Normandy (France). An isotopic disequilibrium is identified during the juvenile portion of the shell. Isotopic disequilibrium is related to kinetic effect due to fast growth rate. Adult oysters mineralize their shells in equilibrium. Juvenile portion of the shell should be avoided for paleoclimatic reconstructions. 
Keywords : stable isotopes, paleoclimatology, sclerogeochemistry, sclerochronology, kinetic isotope effect 


\section{Introduction}

Since the precursor works of Urey (1947) and Epstein et al. (1951), measurement of the oxygen stable isotope composition of carbonates, namely $\delta^{18} \mathrm{O}$, has been the most common approach used to reconstruct past seawater temperatures. These works have shown that in calcium carbonate minerals, the $\delta^{18} \mathrm{O}$ value is a function of both the temperature and the $\delta^{18} \mathrm{O}$ composition of seawater $\left(\delta^{18} \mathrm{O}_{\mathrm{w}}\right)$. In shallow marine environments, this method has been broadly applied to mollusks, as they are potentially long-living organisms and the highresolution measurement of the $\delta^{18} \mathrm{O}$ value of their shells $\left(\delta^{18} \mathrm{O}_{\text {shell }}\right)$ allows for the reconstruction of present and past seasonal gradients of seawater temperatures (e.g. Jones and Quitmyer, 1996; Purton and Brasier, 1997; Kirby et al., 1998; Surge et al. 2001, 2003; Kobashi et al., 2001; Latal et al., 2004; Schöne et al., 2004; Lartaud et al., 2010a; Harzhauser et al., 2011; Wanamaker et al., 2012; Mette et al., 2016; Reynolds et al., 2017; Briard et al., 2020).

One of the prerequisites for using $\delta^{18} \mathrm{O}$ values for (paleo)environmental reconstructions is to determine if the organisms mineralize their shell in isotopic equilibrium with seawater. So-called isotopic disequilibrium has been identified for taxa, such as the coccolithophores, foraminifers or corals (McConnaughey et al., 1997; Spero et al., 1997; Adkins et al., 2003; Hermoso et al., 2016). Isotopic disequilibria are on the contrary reputed to be nonexistent or negligible for most marine mollusk species (Wefer and Berger, 1991; Chauvaud et al., 2005; Schöne et al., 2005; Peharda et al., 2019), although exceptions have been reported for some species, such as deep sea oysters of the genius Pycnodonte (Wisshak et al., 2009) or the giant scallop, Pecten maximus (Owen et al., 2002). Kinetic isotope effects induced by anomalously low or high growth rates have been proposed by these authors, in addition to the combined effects of environmentally 'stressful' conditions (e.g., low 
temperature, low salinity), as causes of disruptions in isotopic equilibrium (Owen et al., 2008; Lartaud et al., 2010c). Finally, a recent study demonstrates that most of biogenic carbonates do not unequivocally precipitate at isotopic equilibrium and suggests revising the classic thermodynamic model (Daëron et al., 2019).

In depth work is thus required to characterize the conditions under which mollusks form their shells at isotopic equilibrium. Among the mollusk shells used as environmental archives, shallow-water oysters are considered as important model species, as many studies have shown that their oxygen stable isotope signature can provide reliable information about their living conditions using oxygen stable isotopes geochemistry (Wefer and Berger, 1991; Richardson et al., 1993; Kirby et al., 1998; Surge et al. 2001, 2003; Lécuyer et al., 2004; Lartaud et al., 2010a, 2010b; Ullmann et al. 2010; Tynan et al. 2014), or magnesium-calcium ratios (Surge and Lohmann, 2008; Mouchi et al., 2013; Tynan et al., 2017). Oysters are ubiquitous and abundant organisms found in shallow marine and brackish deposits since the Jurassic and mineralize their shells with calcite materials, making them resistant to diagenesis. Oyster shells are thus commonly used to reconstruct the mean annual and seasonal gradient of paleotemperatures of near shore environments (Kirby et al., 1998; Kirby, 2000, 2001; Brigaud et al., 2008; Lartaud et al., 2010a; Harzhauser et al., 2011; Huyghe et al., 2012; Briard et al., 2020).

To use shell material as a (paleo)environmental parameter archive, a precise growth chronology allowing to properly refer each carbonate micro-sampling to a calendar date must be determined. This type of approach is widely used in bivalve shells such as Arctica islandica or Pecten maximus that mineralize one increment each year and each day during part of the year respectively (Schöne et al., 2004; Chauvaud et al., 2005; Mette et al., 2016). On the contrary, it was demonstrated that oysters do not precipitate calcitic increments at regular time intervals throughout their life (i.e., several growth anomalies were reported 
during the juvenile period while growth is strongly tidal related after; Huyghe et al., 2019). Thus, to get around this limit, we used mark and recapture experiments based on regular chemical staining of shells, combined with sclerochronological techniques (Lartaud et al., 2010d; Nedoncelle et al., 2013). The resulting shell growth model revealed under cathodoluminescence (CL) observations, demonstrated the validity of using this type of biogenic material (Langlet et al., 2006; Lartaud et al., 2010d). This growth model, significantly revised by Huyghe et al. (2019) provides a suitable framework to test if mineralization occurs in isotopic equilibrium during the entire specimen lifetime. .

\section{Materials and methods}

\subsection{The Magallana gigas oyster}

This work focuses on the analysis of oysters of the species Magallana gigas, which corresponds to the former Crassostrea gigas (Salvi and Mariottini, 2017). These oysters are widely raised commercially in shallow water environments. They tolerate large variations of water salinity, temperature and turbidity. Magallana gigas oysters are suspension feeders and sequentially hermaphrodites, reaching sexual maturity at 12 to 18 months in the studied area (Soletchnik et al., 1996). Reproduction occurs during summer on the French Atlantic coast, but in the location of this work, in the English Channel, the temperature generally remains too cold for reproduction (Ropert et al., 2007), which forces shellfish-farmers to import spats from more southern French locations. In the present study, we consider specimens of less than 12 months as juveniles (i.e. before summer 2005) and specimens older than 12 months as subadults according to the age when sexual maturity starts for these oysters. 
123

124

Young oysters ( $<6$ months old) were reared for 2 years in an experimental site of the Institut Français de Recherche pour l'Exploitation de la Mer (IFREMER), located on the Normandy coast of the English Channel, at the Baie des Veys (BDV, 49²3.110'N $1^{\circ} 6.050$ 'W), following the protocol described in Lartaud et al. (2010d). The BDV is an open bay characterized by a high intertidal setting and semi-diurnal tide regime (Huyghe et al., 2019). Young (<6 months) and small-sized $(<2 \mathrm{~cm})$ specimens of $M$. gigas were collected from wild broodstock at the Arcachon Basin (Gironde, France), at the end of January 2005 and were then transferred to the BDV for growth experiments. The shells were cultivated on oyster tables from the January 28, 2005 to November 28, 2006. Oysters were reared on tables $50 \mathrm{~cm}$ above the sediment. Maximum water depth was $6 \mathrm{~m}$ above the tables and they were emerged during maximum 3 hours per day during periods of low waters spring tides (Huyghe et al., 2019). Hourly measurements of seawater temperature and salinity were directly conducted at the sampled oyster for this study using a multi-parameter probe (YSI data logger, IFREMER) from January 2005 to November 2006 (Huyghe et al., 2019; Fig. 1). The water temperature on the oyster tables ranged from 4.8 to $20{ }^{\circ} \mathrm{C}$ and fluctuated seasonally with mean summer (July to September) and winter (January to March) temperatures of 18.7 \pm 0.6 and $6.7 \pm 1.1{ }^{\circ} \mathrm{C}$ respectively (Huyghe et al., 2019; Fig. 1). Salinity remained quite stable over the year $(33.3 \pm 0.7)$ and displayed only episodic freshwater inputs, which reduced values to 28.8, following heavy rainfalls (Fig. 1).

To assign a growth calendar and link the isotope records of biogenic calcite material with the fluctuation of the environmental parameters, we used a mark and recapture technique combined with the sclerochronological analysis of shells (Lartaud et al., 2010d; Huyghe et al., 
2019). Oyster shells were stained at nearly regular intervals (i.e., 15 times during the whole breeding phase) on site with $\mathrm{Mn}^{2+}$ following the protocol of Langlet et al. (2006). For each staining, oysters were immersed for 4 hours during low tide in a tank filled with seawater in which 90 mg. ${ }^{-1}$ of manganese chloride tetrahydrate $\left(\mathrm{MnCl}_{2} \cdot 4 \mathrm{H}_{2} \mathrm{O}\right)$ was added. Oysters were sampled in November 2006 and shells were then sectioned and mounted on thin sections for CL observations. Rapid incorporation of $\mathrm{Mn}^{2+}$ into the shell calcite appeared as highly luminescent micro-growth bands under CL (Fig. 2; Langlet et al., 2006; Barbin et al., 2008). The identification of the successive $\mathrm{Mn}^{2+}$-markings and the use of tidal CL increments in shell sections allowed for the determination of growth rates over the corresponding time intervals and the identification of a high-resolution calendar growth profile (Fig. 2; Huyghe et al., 2019).

\subsection{Shell preparation and isotope analyses}

scrapped and removed from the inner surface of the shell valves. Upon return to the laboratory, the shells were placed in a $6 \%$ solution of hydrogen peroxide $\left(\mathrm{H}_{2} \mathrm{O}_{2}\right)$ for 6 hours to remove any epibionta from the outer shell surfaces, washed in $0.15 \mathrm{~N}$ nitric acid for 20 minutes to dissolve any carbonate based superficial contamination and rinsed in demineralized water. Observations and samplings were made on the hinge area of the oysters that compiles a complete ontogenetic record of both oyster hinge growth and environmental conditions experienced throughout their lives (Lartaud et al., 2010d). The dry left valve of the shell was cut longitudinally along the growth axis at the umbo region, and thin sections were manufactured to expose the preserved internal structures in order to perform CL observation of the foliated low-magnesium calcite of the hinge region. $\mathrm{Mn}^{2+}$ markings were revealed 
171 under CL microscopy observations (Fig. 2) with a cold cathode (Cathodyne-OPEA, 15-20 kV and 200-300 $\mu \mathrm{Am} . \mathrm{mm}^{-2}$ under a pressure of 0.05 Torr).

Shell calcium carbonate samples for $\delta^{18} \mathrm{O}_{\text {shell }}$ analyses were drilled to a depth of 100 $\mu \mathrm{m}$ along each thin section growth profile in the hinge region. We used a $0.3 \mathrm{~mm}$ drill bit and a computer assisted micromill. Samplings were performed at low and constant speed. The corresponding dates for each drilled sample were assigned using the CL growth profile previously described (Fig. 2). The collected carbonate powders were acidified in $100 \%$ $\mathrm{H}_{3} \mathrm{PO}_{4}$ at $50{ }^{\circ} \mathrm{C}$ under vacuum. The $\mathrm{CO}_{2}$ produced was collected and analyzed using a VG Instruments Isoprime mass spectrometer. Isotopic data were reported in conventional delta $(\delta)$ notation relative to the Vienna Pee Dee Belemnite (VPDB). The standard used for the analyses was an internal standard calibrated on the NBS-19. Standard deviation for $\delta^{18} \mathrm{O}$ values was $\pm 0.1 \%$.

\section{4. $\delta^{8} \mathrm{O}$ seawater analyses}

Sub-monthly analyses of seawater oxygen isotopic composition $\left(\delta^{18} \mathrm{O}_{\mathrm{w}}\right)$ were also performed to determine their seasonal variation. We used the method described in Pierre et al. (1994) for water sampling and analyses. The water samples were collected during high tides, above the oyster tables, in $100 \mathrm{ml}$ glass bottles. $\mathrm{CO}_{2}$-water equilibration method of Epstein and Mayeda (1953) was used as the analytical procedure for the $\mathrm{CO}_{2}$ preparation in order to measure the $\delta^{18} \mathrm{O}_{\mathrm{w}}$ values.

The isotopic compositions were determined using a VG Micromass 602 mass spectrometer. The analytical reproducibility was within the range $1 \sigma=0.1 \%$ o for $\delta^{18} \mathrm{O}$ values. The $\delta$ values correspond to the per mil deviation of the sample relative to the SMOW reference and PDB reference respectively. 


\section{Results}

\subsection{Seawater isotopic composition}

201

202

203

204

205

206

207

208

209

Measurements of the $\delta^{18} \mathrm{O}_{\mathrm{w}}$ values are reported on Fig. 1. This parameter exhibited little seasonal variation with a mean value of $-0.1 \pm 0.1 \%$. The minimum value was observed in March 2005 (-0.3\%o), whereas the maximum values occurred in August 2005 and 2006 $(+0.1 \% o) . \delta^{18} \mathrm{O}_{\mathrm{w}}$ values fluctuations are not correlated with temperature $(\mathrm{r}=0.50 ; \mathrm{p}<0.05)$, and reflects salinity values $(\mathrm{r}=0.68 ; \mathrm{p}<0.05)$ that also remained constant on the breeding site.

\section{isotopic equilibrium}

\subsection{Comparison of the shell oxygen isotope ratios with the predicted values at}

Figure 3 reports the time distribution of the $\delta^{18} \mathrm{O}_{\text {shell }}$ values for four oyster shells. They exhibited a large seasonal range but a small inter-shell variability. Except for the high values in February 2005 (-0.2 to $-0.5 \%$ ), values ranged between +1.5 and $+2.2 \%$ in winter and -0.5 $\% o$ and $-1.2 \%$ in summer.

Determining whether shells precipitate in oxygen isotope equilibrium with seawater requires the estimation of the $\delta^{18} \mathrm{O}_{\text {shell }}$ value expected at equilibrium into the shell carbonate lattice from the temperature and $\delta^{18} \mathrm{O}_{\mathrm{w}}$ values measured in the breeding environment. In the following, we consider isotopic equilibrium in the sense of Kim and O'Neil (1997), which is an apparent equilibrium achieved by most of biogenic carbonates as demonstrated by Daëron et al. (2019). According to temperatures monitored at an subdaily time step (Fig. 2) and $\delta^{18} \mathrm{O}_{\mathrm{w}}$ 
222 values measured in the oyster area, $\delta^{18} \mathrm{O}_{\mathrm{c}}$ values expected at equilibrium (i.e., $\delta^{18} \mathrm{O}$ values

223

224

226

227

228

229

230

231

232

233

234

235

236

237

238

239

240

241

242

243

244 245 predicted 1 in Fig. 3) was estimated using the equation of Kim and O'Neil (1997):

$$
\mathrm{T}=18030 /(1000 \ln \alpha+32.17)-273.15 \quad \text { (equation } 1)
$$

$$
\text { with } \left.\alpha=\left(1000+\delta^{18} \mathrm{O}_{\text {shell }}\right) *\left(1000+\delta^{18} \mathrm{O}_{\mathrm{w}}\right) \quad \text { (equation } 2\right)
$$

We converted the $\delta^{18} \mathrm{O}_{\text {shell }}$ expressed in SMOW to PDB value according to the equation of Coplen et al. (1983).

$$
\left.\delta^{18} \mathrm{O}_{\mathrm{c}}(\mathrm{SMOW})=(1.03091) *\left(\delta^{18} \mathrm{O}_{\text {shell }}(\mathrm{PDB})-0.25\right)\right)+30.91(\text { equation } 3)
$$

sampling, which excludes the interpretation of possible high-resolution fluctuations. But, using Lartaud et al. (2010a) relationship between $\delta^{18} \mathrm{O}_{\mathrm{w}}$ values and salinity for various oyster sites from the English Channel and the Atlantic coast of France, including the BDV location, and the subdaily monitoring of salinity in the oyster breeding area, high-resolution $\delta^{18} \mathrm{O}_{\mathrm{w}}$ values were calculated as follows:

where $\delta^{18} \mathrm{O}_{\mathrm{w}}$ is the $\delta^{18} \mathrm{O}$ value of seawater in SMOW and $\mathrm{S}$ the salinity. This approach was used to obtain a second estimation of $\delta^{18} \mathrm{O}$ value expected at equilibrium (i.e., predicted 2 in Fig. 3). 
Both models of predicted $\delta^{18} \mathrm{O}$ values were in good agreement $(\mathrm{r}=0.99 ; \mathrm{p}<0.05)$

247

248

(Fig. 3), showing that the use of an estimation of $\delta^{18} \mathrm{O}_{\mathrm{w}}$ value through salinity measurements is accurate enough for this type of approach in the environmental settings for which the study was conducted.

We observed on Fig. 3 that during the first six months of the experiment, $\delta^{18} \mathrm{O}_{\text {shell }}$ values exhibit a significant shift compared to the predicted values at isotopic equilibrium. First, during January and the beginning of February, $\delta^{18} \mathrm{O}_{\text {shell }}$ values are 0.3 to $1 \%$ o lower than the predicted $\delta^{18} \mathrm{O}$. During the second half of February, the isotopic shift increases with shell values more negative by 1.7 to $3 \%$. Then, from March to June, $\delta^{18} \mathrm{O}_{\text {shell }}$ values remain constant for a given shell, and the shift with the predicted values decreases continuously. Once the organisms reached 1 year old (i.e., during summer 2005), values measured in shells were close to values predicted at isotopic equilibrium.

\section{Discussion}

\subsection{A juvenile isotopic disequilibrium}

The results observed on Fig. 3 suggest that mineralization occurs out of equilibrium for oxygen isotopes during the younger part of the life of oysters (i.e., $<1$ year old). To quantify this disequilibrium compared to theoretical values for calcite and biocalcite, we plotted on Fig. 4 the coefficient of fractionation between water and calcite $\alpha_{\mathrm{c} / \mathrm{w}}$ as a function of the calculated temperature of mineralization. Two distinct equilibriums were considered: (i) the empirical relationship of Kim and O'Neil (1997) for synthetic calcites, and (ii) that of Watkins et al. (2014) and Daëron et al. (2019) for natural slow growing calcites. These 
relationships yield the same dependency on temperature but the Kim and O'Neil (1997) model has a constant offset of $-1.5 \%$. The shell portion mineralized during winter and spring 2005 (i.e., during the most juvenile stage of the oysters in the data set), differs greatly from the equilibrium of both the synthetic and slow growing calcites. Various parameters have been proposed to generate isotopic disequilibria in calcites, such as $\mathrm{pH}$ of seawater, solution saturation and crystallization rate (Watkins et al., 2014; Devriendt et al., 2017). As these environmental parameters did not differ significantly between winter and spring 2005 (i.e., juvenile oysters) and winter and spring 2006 (i.e., adult oysters), it is unlikely that $\mathrm{pH}$ of the seawater or solution saturation could have changed enough to impact the isotopic equilibrium to such a degree. A recent study, which investigated growth patterns of oyster shells from the same spat as the one used in this experiment revealed that during the juvenile part of the shell, growth is characterized by high growth rates (up to $180 \mu \mathrm{m} /$ day in the hinge area), and severe anomalies in the rhythm of deposition of calcite material (Huyghe et al., 2019). Lower $\delta^{18} \mathrm{O}$ values in biogenic material relative to the expected isotopic equilibrium have been suggested to result from kinetic fractionation due to rapid mineralization and the influence of rebalance in the internal fluid $\mathrm{pH}$ on the dissolved inorganic carbon species (McConnaughey et al., 1997; Adkins et al., 2003; Dietzel et al., 2009; Uchikawa and Zeebe, 2012). For example, Rollion-Bard et al. (2008) showed that early precipitated calcite is depleted by $3 \%$ compared to secondary calcite in foraminifera tests, due to elevated $\mathrm{pH}$ in the calcification fluid. Owen et al. (2002) also showed that for $P$. maximus shells, the $\delta^{18} \mathrm{O}_{\text {shell }}$ value is more depleted during fast growth rate intervals and these deviations have been interpreted as resulting from kinetic isotope effects. However, in their work, Owen et al. (2002) described a maximum negative shift in the $\delta^{18} \mathrm{O}_{\text {shell }}$ value of $1 \%$ whereas here the juvenile oyster shells show a maximum negative shift of $3 \%$ (Fig. 3), closer to the isotopic disequilibrium described for corals and foraminifera (Devriendt et al., 2017). Reaching equilibrium between dissolved 
carbonate species and water via hydration and hydroxylation reactions requires a minimum residence time in the calcifying fluid estimated at $1 \mathrm{~h}$ for corals (Rollion-Bard et al., 2003). Staining experiments revealed that calcification occurs in less than 30 min for oysters (Lartaud et al., 2010d). Assuming high growth rates (up to $180 \mu \mathrm{m} /$ day) in a short period of time during the juvenile stage of oysters (Huyghe et al., 2019), conditions for such strong isotopic disequilibrium exist.

The shift observed between measured and predicted $\delta^{18} \mathrm{O}$ values is not constant as the difference between the $\delta^{18} \mathrm{O}_{\text {shell }}$ values of the three shells and the predicted $\delta^{18} \mathrm{O}$ values at equilibrium decreases dramatically until May-June 2005 ( 0.5\%o) (Fig. 3), leading to an $\alpha_{\mathrm{c} / \mathrm{w}}$ closer to the Kim and O'Neil (1997) equilibrium (Fig.4). This is in agreement with strong but highly variable growth rates during the juvenile stages (Huyghe et al., 2019), leading to periods where conditions to reach equilibria are closer. These results support the model of Coplen et al. (2007) and Daëron et al. (2019) for which only carbonates precipitating at very slow rates can precipitate at isotopic equilibrium.

Contrary to the juvenile phase, the shell portion formed in the adult phase ( $>1$ year old) appears consistent with the theoretical isotopic equilibrium of Kim and O'Neil (1997), but still differs substantially from the theoretical and measured equilibrium for slow-growing calcites by Watkins et al. (2014) and Daëron et al. (2019), respectively (Fig. 4). This difference implies that the shells calcify too rapidly to achieve DIC-calcite equilibrium. But as the slopes of the equilibrium regression are the same, we conclude that both the equilibrium limit and the kinetic limit of $\alpha_{\mathrm{c} / \mathrm{w}}$ do not vary significantly with temperature. Although shells do not reach an exact isotopic equilibrium according to Daëron et al. (2019), temperature can be inferred from the Kim and O’Neil (1997) empirical equation. 
After the first year of life, labeled here as the juvenile phase, our results show that

324 oysters mineralize their shells close to the isotopic equilibrium and thus can accurately reflect the seawater temperatures, assuming an independent estimation of the isotopic composition of seawater. This confirms the use of this type of biogenic material as a promising paleoclimate archive, as revealed by the large bibliography on modern and fossil oysters (Kirby et al., 1998; Surge et al., 2001, 2003; Harding et al., 2010; Lartaud et al., 2010a; Harzhauser et al., 2011; Bougeois et al., 2014; Tynan et al., 2014; Huyghe et al., 2015; Briard et al., 2020).

The measured seawater temperatures were plotted versus the difference between $\delta^{18} \mathrm{O}_{\text {shell }}$ values of oyster shells and the $\delta^{18} \mathrm{O}_{\mathrm{w}}$ values estimated through salinity monitoring (equation 4) (Fig. 5). The data for the juvenile phase (February to June 2005) were excluded, as the oysters did not mineralize their shell in isotopic equilibrium during this interval. A negative linear correlation was found between the shell and seawater oxygen isotopes differences $\left(\delta^{18} \mathrm{O}_{\text {shell }}-\delta^{18} \mathrm{O}_{\mathrm{w}}\right)$ and the seawater temperatures measured by the probes deployed in situ (least mean squares regression, $\mathrm{R}^{2}=0.87, \mathrm{p}<0.05, \mathrm{n}=60$ ):

\section{With $\delta^{18} \mathrm{O}_{\text {shell }}$ in PDB and $\delta^{18} \mathrm{O}_{\mathrm{w}}$ in SMOW.}

Different types of equations to link the $\delta^{18} \mathrm{O}$ values of calcitic bivalve shells to temperatures exist, with the most currently used are those from Friedman and O'Neil (1977) and Kim and O'Neil, (1997), based on synthetic calcite, and Anderson and Arthur (1983), established from various carbonates including mollusk shells. Figure 6 reports the seawater temperature measured at the BDV over the studied interval compared to the temperatures 
calculated from the $\delta^{18} \mathrm{O}$ values of the four combined shells according to different equations.

\section{7}

Kim and O'Neil (1997) (equation 2) and the one issued from this study (equation 5) were used, as well as the equation 6 of Friedman and O'Neil (1977) modified from Tarutani et al. (1969):

and the equation 8 resulting from Anderson and Arthur (1983):

$$
1000 \ln \alpha=\left(2.78 * 10^{6}\right) / \mathrm{T}^{2}(\mathrm{~K})-2.89 \text { (equation 6) }
$$$$
\text { with } \alpha=\left(\delta^{18} \mathrm{O}_{\text {shell SMOw }}+1000\right) /\left(\delta^{18} \mathrm{O}_{\mathrm{w}} \text { SMOw }+1000\right)(\text { equation } 7)
$$

\footnotetext{
$$
\text { and the equation } 8 \text { resulting from Anderson and Arthur (1983): }
$$
}


seasonal variations. As the temperatures estimated by these two equations differ on average by only $0.6{ }^{\circ} \mathrm{C}$ during winter and $0.9{ }^{\circ} \mathrm{C}$ during summer, we suggest using preferentially the equation of Kim and O'Neil (1997) which is already widespread in the literature.

In addition, the reconstructed temperatures based on oxygen isotopes highlitgh that oyster are able to mineralize their shells during winter in seawater temperatures as cold as 5.7 ${ }^{\circ} \mathrm{C}$. This value is close to the minimum temperature for oyster biomineralization proposed by Ullmann et al. (2010), deduced from stable isotopes analysis, and by Huyghe et al. (2019) from counting growth increment.

\section{Conclusions}

\section{Oxygen isotope measurements of oyster shells of the species Magallana gigas enabled} us to identify the parameters controlling the stable isotope composition in their shells. We demonstrate that oysters mineralize their shell at isotopic equilibrium during the adult part of their life (i.e., specimens more than one year old). Oysters shells are thus reliable archives of their living conditions and can be used to accurately reconstruct the seasonal temperature gradient in their environment, even in winter seawater temperatures below $6{ }^{\circ} \mathrm{C}$. The comparison between measured in situ temperatures and the temperatures calculated from equations provided by previous studies indicates that the equation of Kim and O'Neil (1997) yields accurate summer and winter temperatures. On the contrary, the equations of Anderson and Arthur (1983) and Friedman and O’Neil (1977) over-estimates winter temperatures by $\sim 2$ ${ }^{\circ} \mathrm{C}$, which does not reliably constrain the seasonal range of temperature.

During the juvenile period, (i.e., during the first year of life), an isotopic fractionation was observed for the $\delta^{18} \mathrm{O}$ values. This shift is maximum during the younger part of the shell 
observed (corresponding to winter here), and is contemporaneous with anomalous high growth peaks. This deviation can be explained by a kinetic isotope effect due to very high growth rates. We thus recommend avoiding the juvenile interval of oyster shells to reconstruct reliable temperatures. Further works are required to investigate if this kind of isotopic disequilibria associated to the juvenile period can be observed in other species than oysters.

\section{Acknowledgments}

This work was financially supported by the ANR Amor 'Data Model Reconstruction of the Cenozoic Climate' and the BQR project from Sorbonne Université, 'High frequency to very high frequency recordings of environmental changes to climate by biomineralization.' We thank IFREMER for the use of oyster breeding facilities and for their help with the field work. Special thanks may be due to Brian Mitchell for improving the English of the manuscript.

\section{Contributors}

FL, LE, MdR and MRe designed the study. DH, LE, MdR, MRo and FL conducted the field work, and NL and LE carried out the stable isotope analyses. DH and FL wrote the paper. All authors contributed critically to the drafts and gave final approval for publication.

Conflict of interest: The authors declare that they have no conflict of interest.

Ethical approval: All applicable international, national, and/or institutional guidelines for the care and use of animals were followed. 


\section{References}

424

Adkins, J.F., Boyle, E.A., Curry, W.B., Lutringer, A., 2003. Stable isotopes in deep-sea corals and a new mechanism for "vital effects." Geochim. Cosmochim. Acta 67, 1129-1143.

Anderson, T.F., Arthur, M.A., 1983. Stable isotopes of oxygen and carbon and their application to sedimentologic and paleoenvironmental problems. In: ARTHUR, M.A., ANDERSON, T.F., KAPLAN, I.R., VeIZER, J. \& LAND, L.S. (eds) Stable Isotopes in Sedimentary Geology. Society of Economic Paleontologists and Mineralogists, Short Course Notes, 10, 1.1-1.151.

Barbin, V., Ramseyer, K., Elfman, M., 2008. Biological record of added manganese in seawater: a new efficient tool to mark in vivo growth lines in the oyster species Crassostrea gigas. Int. J. Earth Sci. 97, 193-199.

Bougeois, L., De Rafélis, M., Reichart, G.-J., De Nooijer, L.J., Nicollin, F., Dupont-Nivet, G., 2014. A high resolution study of trace elements and stable isotopes in oyster shells to estimate Central Asian Middle Eocene seasonality. Chem. Geol. 363, 200-212.

Briard, J., Pucéat, E., Vennin, E., Daëron, M., Chavagnac, V., Jaillet, R., Merle, D., de Rafélis, M., 2020. Seawater paleotemperature and paleosalinity evolution in neritic environments of the Mediterranean margin: Insights from isotope analysis of bivalve shells. Palaeogeogr. Palaeoclimatol. Palaeoecol. 543, 109582.

Brigaud, B., Pucéat, E., Pellenard, P., Vincent, B., Joachimski, M.M., 2008. Climatic fluctuations and seasonality during the Late Jurassic (Oxfordian-Early Kimmeridgian) inferred from $\delta^{18} \mathrm{O}$ of Paris Basin oyster shells. Earth and Planetary Science Letters, 273(1-2), 58-67.

Coplen, T.B., Kendall, C., Hopple, J., 1983. Comparison of stable isotope reference samples. Nature, 302(5905), 236-238.

Coplen, T.B., 2007. Calibration of the calcite-water oxygen-isotope geothermometer at Devils Hole, Nevada, a natural laboratory. Geochim. Cosmochim. Acta 71, 3948-3957. 
Daëron, M., Drysdale, R.N., Peral, M., Huyghe, D., Blamart, D., Coplen, T.B., Lartaud, F., Zanchetta, G., 2019. Most Earth-surface calcites precipitate out of isotopic equilibrium. Nat. Commun. $10,429$.

Devriendt, L.S., Watkins, J.M., McGregor, H.V., 2017. Oxygen isotope fractionation in the $\mathrm{CaCO}_{3^{-}}$ DIC- $\mathrm{H}_{2} \mathrm{O}$ system. Geochim. Cosmochim. Acta 214, 115-142.

Dietzel, M., Tang, J., Leis, A., Köhler, S.J., 2009. Oxygen isotopic fractionation during inorganic calcite precipitation-Effects of temperature, precipitation rate and $\mathrm{pH}$. Chem. Geol. 268, $107-115$.

Epstein, S., Buchsbaum, R., Lowenstam, H., Urey, H.C., 1951. Carbonate-water isotopic temperature scale. Geol. Soc. Am. Bull. 62, 417-426.

Epstein, S., Mayeda, T., 1953. Variation of $\mathrm{O}^{18}$ content of waters from natural sources. Geochim. Cosmochim. Acta 4, 213-224.

Friedman, I., O'Neil, J.R., 1977. Compilation of stable isotope fractionation factors of geochemical interest (Vol. 440). US Government Printing Office.

Harding, J.M., Spero, H.J., Mann, R., Herbert, G.S., Sliko, J.L., 2010. Reconstructing early $17^{\text {th }}$ century estuarine drought conditions from Jamestown oysters. Proceedings of the National Academy of Sciences of the United States of America 107, 10549-10554.

Harzhauser, M., Piller, W.E., Müllegger, S., Grunert, P., Micheels, A., 2011. Changing seasonality patterns in Central Europe from Miocene Climate Optimum to Miocene Climate Transition deduced from the Crassostrea isotope archive. Glob. Planet. Change 76, 77-84.

Hermoso, M., Minoletti, F., Aloisi, G., Bonifacie, M., McClelland, H.L.O., Labourdette, N., Renforth, P., Chaduteau, C., Rickaby, R.E., 2016. An explanation for the ${ }^{18} \mathrm{O}$ excess in Noelaerhabdaceae coccolith calcite. Geochim. Cosmochim. Acta 189, 132-142.

Huyghe, D., Merle, D., Lartaud, F., Cheype, E., Emmanuel, L., 2012. Middle Lutetian climate in the Paris Basin: implications for a marine hotspot of paleobiodiversity. Facies 58, 587-604.

Huyghe, D., Lartaud, F., Emmanuel, L., Merle, D., Renard, M., 2015. Palaeogene climate evolution in the Paris Basin from oxygen stable isotope $\left(\delta^{18} \mathrm{O}\right)$ compositions of marine molluscs. J. Geol. Soc. $172,576-587$. 
Huyghe, D., de Rafelis, M., Ropert, M., Mouchi, V., Emmanuel, L., Renard, M., Lartaud, F., 2019. New insights into oyster high-resolution hinge growth patterns. Mar. Biol. 166, 48. https://doi.org/10.1007/s00227-019-3496-2

Jones, D.S., Quitmyer, I.R., 1996. Marking time with bivalve shells: oxygen isotopes and season of annual increment formation. Palaios, 340-346.

Kim, S.-T., O’Neil, J.R., 1997. Equilibrium and nonequilibrium oxygen isotope effects in synthetic carbonates. Geochim. Cosmochim. Acta 61, 3461-3475.

Kirby, M.X., Soniat, T.M., Spero, H.J., 1998. Stable isotope sclerochronology of Pleistocene and Recent oyster shells (Crassostrea virginica). Palaios 13, 560-569.

Kirby, M.X., 2000. Paleoecological differences between Tertiary and Quaternary Crassostrea oysters, as revealed by stable isotope sclerochronology. Palaios, 15(2), 132-141.

Kirby, M.X., 2001. Differences in growth rate and environment between Tertiary and Quaternary Crassostrea oysters. Paleobiology, 27(1), 84-103.

Kobashi, T., Grossman, E.L., Yancey, T.E., Dockery III, D.T., 2001. Reevaluation of conflicting Eocene tropical temperature estimates: Molluskan oxygen isotope evidence for warm low latitudes. Geology 29, 983-986.

Langlet, D., Alunno-Bruscia, M., Rafélis, M., Renard, M., Roux, M., Schein, E., Buestel, D., 2006. Experimental and natural cathodoluminescence in the shell of Crassostrea gigas from Thau lagoon (France): ecological and environmental implications. Mar. Ecol. Prog. Ser. 317, 143156.

Lartaud, F., Emmanuel, L., De Rafélis, M., Ropert, M., Labourdette, N., Richardson, C.A., Renard, M., 2010a. A latitudinal gradient of seasonal temperature variation recorded in oyster shells from the coastal waters of France and The Netherlands. Facies 56, 13.

Lartaud, F., Emmanuel, L., De Rafélis, M., Pouvreau, S., Renard, M., 2010b. Influence of food supply on the $\delta^{13} \mathrm{C}$ signature of mollusc shells: implications for palaeoenvironmental reconstitutions. Geo-Mar. Lett. 30, 23-34.

Lartaud, F., Chauvaud, L., Richard, J., Toulot, A., Bollinger, C., Testut, L., Paulet, Y.-M., 2010c. Experimental growth pattern calibration of Antarctic scallop shells (Adamussium colbecki, 
Smith 1902) to provide a biogenic archive of high-resolution records of environmental and climatic changes. J. Exp. Mar. Biol. Ecol. 393, 158-167.

506

507

508

509

510

511

512

513

514

515

516

517

518

519

520

521

522

523

524

525

526

527

528

529

Lartaud, F., de Rafelis, M., Ropert, M., Emmanuel, L., Geairon, P., Renard, M., 2010d. Mn labelling of living oysters: Artificial and natural cathodoluminescence analyses as a tool for age and growth rate determination of C. gigas (Thunberg, 1793) shells. Aquaculture 300, 206-217. https://doi.org/10.1016/j.aquaculture.2009.12.018

Latal, C., Piller, W., Harzhauser, M., 2004. Palaeoenvironmental reconstructions by stable isotopes of Middle Miocene gastropods of the Central Paratethys. Palaeogeogr. Palaeoclimatol. Palaeoecol. 211, 157-169. https://doi.org/10.1016/S0031-0182(04)00260-3

Lécuyer, C., Reynard, B., Martineau, F., 2004. Stable isotope fractionation between mollusc shells and marine waters from Martinique Island. Chem. Geol. 213, 293-305.

McConnaughey, T.A., Burdett, J., Whelan, J.F., Paull, C.K., 1997. Carbon isotopes in biological carbonates: Respiration and photosynthesis. Geochim. Cosmochim. Acta 61, 611-622. https://doi.org/10.1016/S0016-7037(96)00361-4

Mette, M.J., Wanamaker, A.D., Jr., Carroll, M.L., Ambrose, W.G., Jr. Retelle, M.J., 2016. Linking large-scale climate variability with Arctica islandica shell growth and geochemistry in northern Norway. Limnology and Oceanography, 61, 748-764.

Mouchi, V., De Rafélis, M., Lartaud, F., Fialin, M., Verrecchia, E., 2013. Chemical labelling of oyster shells used for time-calibrated high-resolution $\mathrm{Mg} / \mathrm{Ca}$ ratios: a tool for estimation of past seasonal temperature variations. Palaeogeogr. Palaeoclimatol. Palaeoecol. 373, 66-74.

Nedoncelle, K., Lartaud, F., de Rafelis, M., Boulila, S., Le Bris, N., 2013. A new method for highresolution bivalve growth rate studies in hydrothermal environments. Mar. Biol. 160, 14271439. https://doi.org/10.1007/s00227-013-2195-7

Owen, R., Kennedy, H., Richardson, C., 2002. Isotopic partitioning between scallop shell calcite and seawater: effect of shell growth rate. Geochim. Cosmochim. Acta 66, 1727-1737. https://doi.org/10.1016/S0016-7037(01)00882-1 
Owen, E.F., Wanamaker, A.D., Feindel, S.C., Schöne, B.R., Rawson, P.D., 2008. Stable carbon and oxygen isotope fractionation in bivalve (Placopecten magellanicus) larval aragonite. Geochim. Cosmochim. Acta 72, 4687-4698. https://doi.org/10.1016/j.gca.2008.06.029

Peharda, M., Thébault, J., Markulin, K., Schöne, B.R., Janeković, I., Chauvaud, L., 2019. Contrasting shell growth strategies in two Mediterranean bivalves revealed by oxygen-isotope ratio geochemistry: the case of Pecten jacobaeus and Glycymeris pilosa. Chemical Geology, 526, 23-35.

Pierre, C., Vangriesheim, A., Laube-Lenfant, E., 1994. Variability of water masses and of organic production-regeneration systems as related to eutrophic, mesotropic and oligotrophic conditions in the northeast Atlantic Ocean. J. Mar. Syst. 5, 159-170. https://doi.org/10.1016/0924-7963(94)90029-9

Purton, L., Brasier, M., 1997. Gastropod carbonate $\delta^{18} \mathrm{O}$ and $\delta^{13} \mathrm{C}$ values record strong seasonal productivity and stratification shifts during the late Eocene in England. Geology 871-874.

Richardson, C.A., Collis, S.A., Ekaratne, K., Dare, P., Key, D., 1993. The age determination and growth rate of the European flat oyster, Ostrea edulis, in British waters determined from acetate peels of umbo growth lines. ICES J. Mar. Sci. 50(4): 493-500

Rollion-Bard, C., Chaussidon, M., France-Lanord, C., 2003. pH control on oxygen isotopic composition of symbiotic corals. Earth Planet. Sci. Lett 215, 265-273.

Rollion-Bard, C., Erez, J., Zilberman, T., 2008. Intra-shell oxygen isotope ratios in the benthic foraminifera genus Amphistegina and the influence of seawater carbonate chemistry and temperature on this ratio. Geochim. Cosmochim. Acta 72, 6006-6014.

Ropert, M., Pien, S., Mary, C., Bouchaud, B., 2007. Rapport REMONOR, Résultats 2006.

Reynolds, D.J., Hall, I.R., Slater, S.M., Scourse, J.D., Halloran, P.R. Sayer, M.D.J., 2017. Reconstructing Past Seasonal to Multicentennial-Scale Variability in the NE Atlantic Ocean Using the Long-Lived Marine Bivalve Mollusk Glycymeris glycymeris. Paleoceanography, $32,1153-1173$.

Salvi, D., Mariottini, P., 2017. Molecular taxonomy in 2D: a novel ITS2 rRNA sequence-structure approach guides the description of the oysters' subfamily Saccostreinae and the genus 
Magallana (Bivalvia: Ostreidae). Zool. J. Linn. Soc. 179, 263-276. https://doi.org/10.1111/zoj.12455

560

561

562

563

564

565

566

567

568

569

570

571

572

573

574

575

576

577

578

579

580

581

582

583

584

585

Schöne, B.R., Castro, A.D.F., Fiebig, J., Houk, S.D., Oschmann, W., Kröncke, I., 2004. Sea surface water temperatures over the period 1884-1983 reconstructed from oxygen isotope ratios of a bivalve mollusk shell (Arctica islandica, southern North Sea). Palaeogeogr. Palaeoclimatol. Palaeoecol. 212(3-4), 215-232.

Schöne, B.R., Fiebig, J., Pfeiffer, M., Gleß, R., Hickson, J., Johnson, A.L.A., Dreyer, W., Oschmann, W., 2005. Climate records from a bivalved Methuselah (Arctica islandica, Mollusca; Iceland). Palaeogeogr. Palaeoclimatol. Palaeoecol. 228, 130-148.

Soletchnik, P., Geairon, P., Razet, D., Goulletquer, P., 1996. Physiologie de la maturation et de la ponte chez l'huitre creuse Crassostrea gigas (Rapport Ifremer).

Spero, H.J., Bijma, J., Lea, D.W., Bemis, B.E., 1997. Effect of seawater carbonate concentration on foraminiferal carbon and oxygen isotopes. Nature 390, 497-500. https://doi.org/10.1038/37333

Surge, D., Lohmann, K.C., Dettman, D.L., 2001. Controls on isotopic chemistry of the American oyster, Crassostrea virginica: implications for growth patterns. Palaeogeogr. Palaeoclimatol. Palaeoecol. 172, 283-296. https://doi.org/10.1016/S0031-0182(01)00303-0

Surge, D.M., Lohmann, K.C., Goodfriend, G.A., 2003. Reconstructing estuarine conditions: oyster shells as recorders of environmental change, Southwest Florida. Estuar. Coast. Shelf Sci., 57(5-6), 737-756.

Surge, D., Lohmann, K.C., 2008. Evaluating $\mathrm{Mg} / \mathrm{Ca}$ ratios as a temperature proxy in the estuarine oyster, Crassostrea virginica. J. Geophys. Res. Biogeosci. 113 (G2)

Tarutani, T., Clayton, R.N., Mayeda, T.K., 1969. The effect of polymorphism and magnesium substitution on oxygen isotope fractionation between calcium carbonate and water. Geochimica et Cosmochimica Acta, 33(8), 987-996.

Tynan, S., Dutton, A., Eggins, S., Opdyke, B., 2014. Oxygen isotope records of the Australian flat oyster (Ostrea angasi) as a potential temperature archive. Mar. Geol. 357, 195-209. https://doi.org/10.1016/j.margeo.2014.07.009 
Tynan, S., Opdyke, B.N., Walczak, M., Eggins, S., Dutton, A., 2017) Assessment of Mg/Ca in Saccostrea glomerata (the Sydney rock oyster) shell as a potential temperature record. Palaeogeography, palaeoclimatology, palaeoecology, 484, 79-88.

Uchikawa, J., Zeebe, R.E., 2012. The effect of carbonic anhydrase on the kinetics and equilibrium of the oxygen isotope exchange in the $\mathrm{CO}_{2}-\mathrm{H}_{2} \mathrm{O}$ system: Implications for $\delta^{18} \mathrm{O}$ vital effects in biogenic carbonates. Geochim. Cosmochim. Acta 95, 15-34. https://doi.org/10.1016/j.gca.2012.07.022

Ullmann, C.V., Wiechert, U., Korte, C., 2010. Oxygen isotope fluctuations in a modern North Sea oyster (Crassostrea gigas) compared with annual variations in seawater temperature: Implications for palaeoclimate studies. Chem. Geol. 277, 160-166. https://doi.org/10.1016/j.chemgeo.2010.07.019

Urey, H.C., 1947. The thermodynamic properties of isotopic substances. J. Chem. Soc. Resumed 562581. https://doi.org/10.1039/JR9470000562

Wanamaker, A.D., Jr., Butler, P.G., Scourse, J.D., Heinemeier, J., Eiriksson, J., Knudsen, K.L. Richardson, C.A., 2012. Surface changes in the North Atlantic meridional overturning circulation during the last millennium. Nat Commun, 3, 899.

Watkins, J.M., Hunt, J.D., Ryerson, F.J., DePaolo, D.J., 2014. The influence of temperature, pH, and growth rate on the $\delta^{18} \mathrm{O}$ composition of inorganically precipitated calcite. Earth Planet. Sci. Lett. 404, 332-343. https://doi.org/10.1016/j.eps1.2014.07.036

Wefer, G., Berger, W.H., 1991. Isotope paleontology: growth and composition of extant calcareous species. Mar. Geol., Anoxic Basins and Sapropel Deposition in the Eastern Mediterranean: Past and Present 100, 207-248. https://doi.org/10.1016/0025-3227(91)90234-U

Wisshak, M., López Correa, M., Gofas, S., Salas, C., Taviani, M., Jakobsen, J., Freiwald, A., 2009. Shell architecture, element composition, and stable isotope signature of the giant deep-sea oyster Neopycnodonte zibrowii sp. n. from the NE Atlantic. Deep Sea Res. Part Oceanogr. Res. Pap. 56, 374-407. https://doi.org/10.1016/j.dsr.2008.10.002 
Figure caption

614

615

616

617

618

619

620

621

622

623

624

625

626

627

628

629

630

631

632

633

634

635

Figure 1: Fluctuation of seawater temperature, salinity (from Huyghe et al., 2019) and $\delta^{18} \mathrm{O}$ composition of seawater measured above the oyster tables in the Baie des Veys, Normandy, France.

Figure 2: Illustration of the attribution of an absolute chronological framework to the samplings over the hinge area. A: section of the right part of the hinge area under natural light and illustration of the samplings for stable isotope analyses. The location of the 15 chemical markings are also reported. B: observation of the left section of the hinge under cathodoluminescence allowing for the identification of the $\mathrm{Mn}^{2+}$ markings. $\mathrm{C}$ : cathodoluminescence profile measured (arbitrary units, AU) along the profile reported in B (white dotted line). High luminescent values correspond to the $\mathrm{Mn}^{2+}$ markings. The horizontal axis corresponds to the length measured along the hinge. D: conversion of the length to calendar dates given the dates of the markings and from the counting of the tidal influenced calcitic increments. Horizontal red lines illustrate the fluctuation in the duration of each isotope sample according to the period considered.

Figure 3: Variation through time of the $\delta^{18} \mathrm{O}$ of the four shells analyzed. The $\delta^{18} \mathrm{O}$ values at isotopic equilibrium predicted from Kim and O'Neil (1997) and calculated from the $\delta^{18} \mathrm{O}$ of seawater are shown by the red diamonds $\left(\delta^{18} \mathrm{O}\right.$ predicted 1$)$. The $\delta^{18} \mathrm{O}$ values calculated from salinity values are shown by the grey line $\left(\delta^{18} \mathrm{O}\right.$ predicted 2$)$. Note that the vertical (y) axis is inverted. 
637 Figure 4: Correlation between the calculated temperatures from $\delta^{18} \mathrm{O}$ of oysters shells using 638 the equation of Kim and O'Neil (1997) and the fractionation coefficient between calcite and 639 water $\alpha_{\mathrm{c} / \mathrm{w}}$. Comparison is made with the theoretical isotopic equilibrium of Kim and O'Neil 640 (1997) (dotted line) and the equilibrium of slow growing calcites, calculated by Watkins et al. 641 (2014) and Daëron et al. (2019). This comparison highlights that juvenile oyster samples were 642 mineralized out of equilibrium.

643

644 Figure 5: Temperature equation proposed according to the oxygen isotopes of oyster shells 645 from for the Baie des Veys. Values before July 2005, when shells mineralized out of isotopic 646 equilibrium during the juvenile period, were excluded from the correlation.

647

648 Figure 6: Fluctuation over time of the measured seawater temperatures (from Huyghe et al., 649 2019) and the temperatures calculated from the $\delta^{18} \mathrm{O}$ values of oyster shells using the 650 equations of Friedman and O’Neil (1977), Kim and O’Neil (1997), Anderson and Arthur 651 (1983) and the equation determined from this study. 


\section{$\mathrm{Mn}^{2+}$ markings}

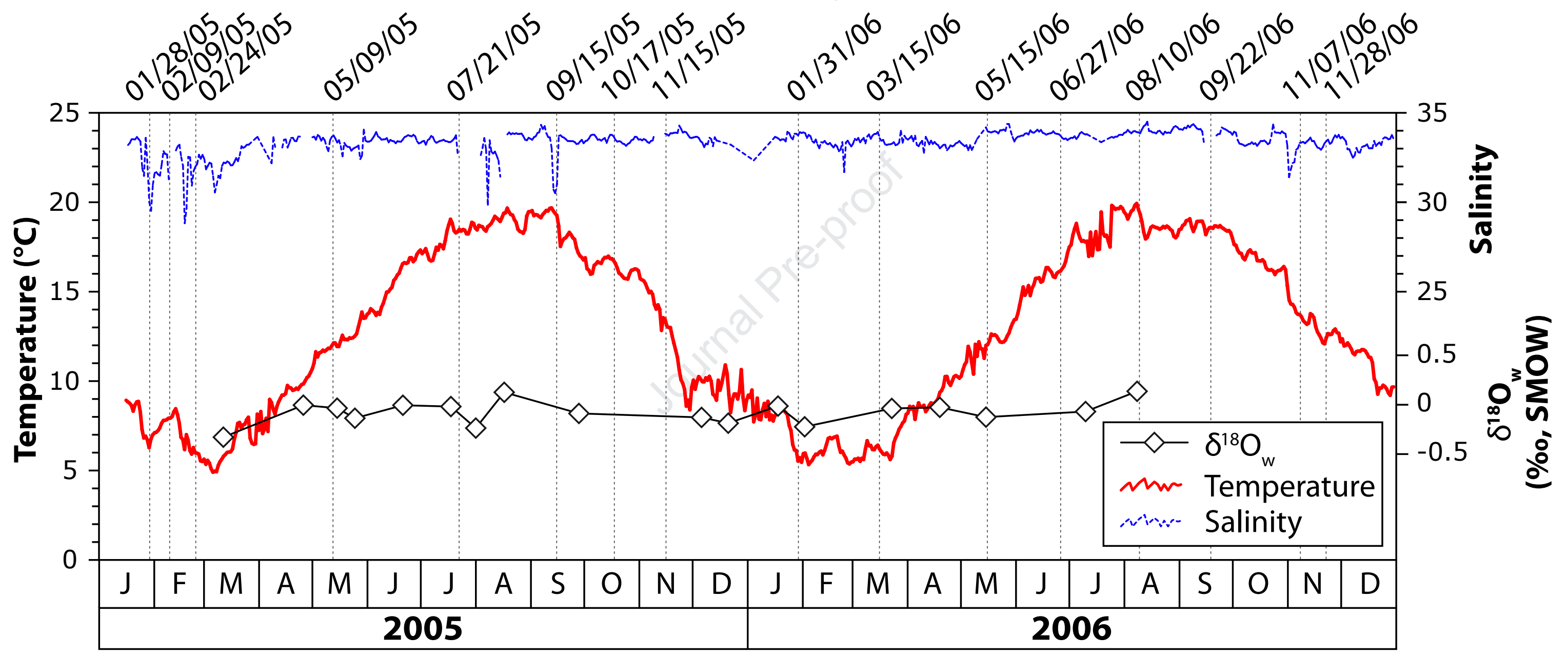




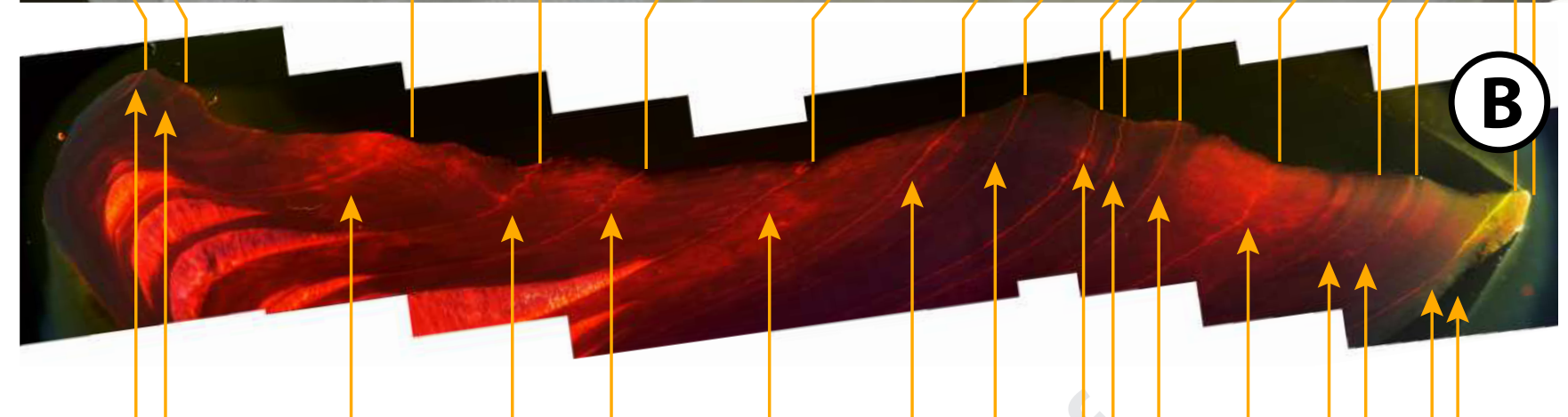

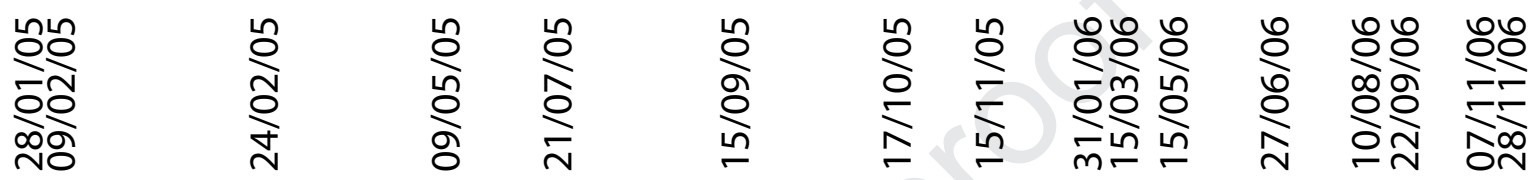

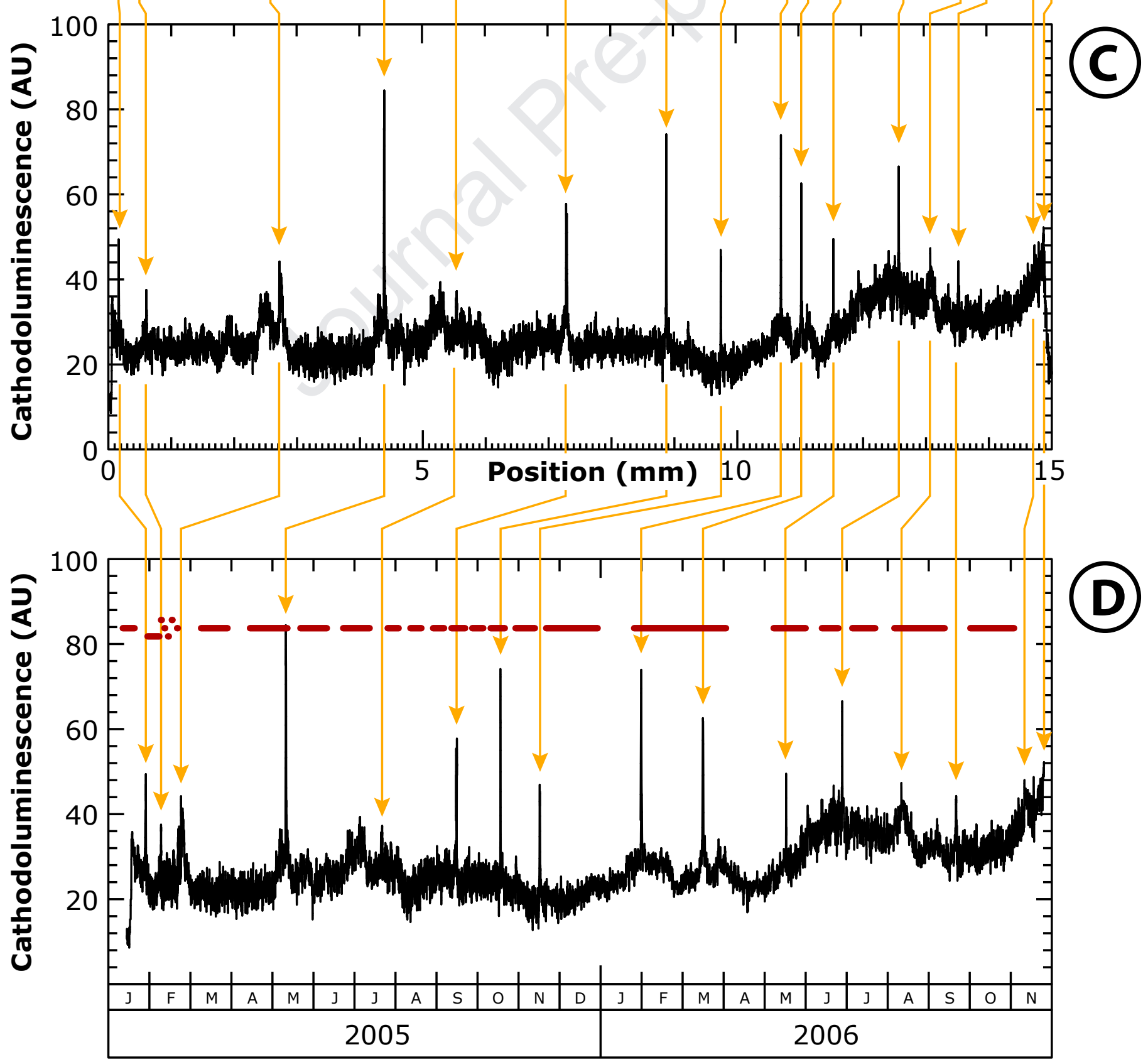

\section{Date}




\section{$\mathrm{Mn}^{2+}$ markings}

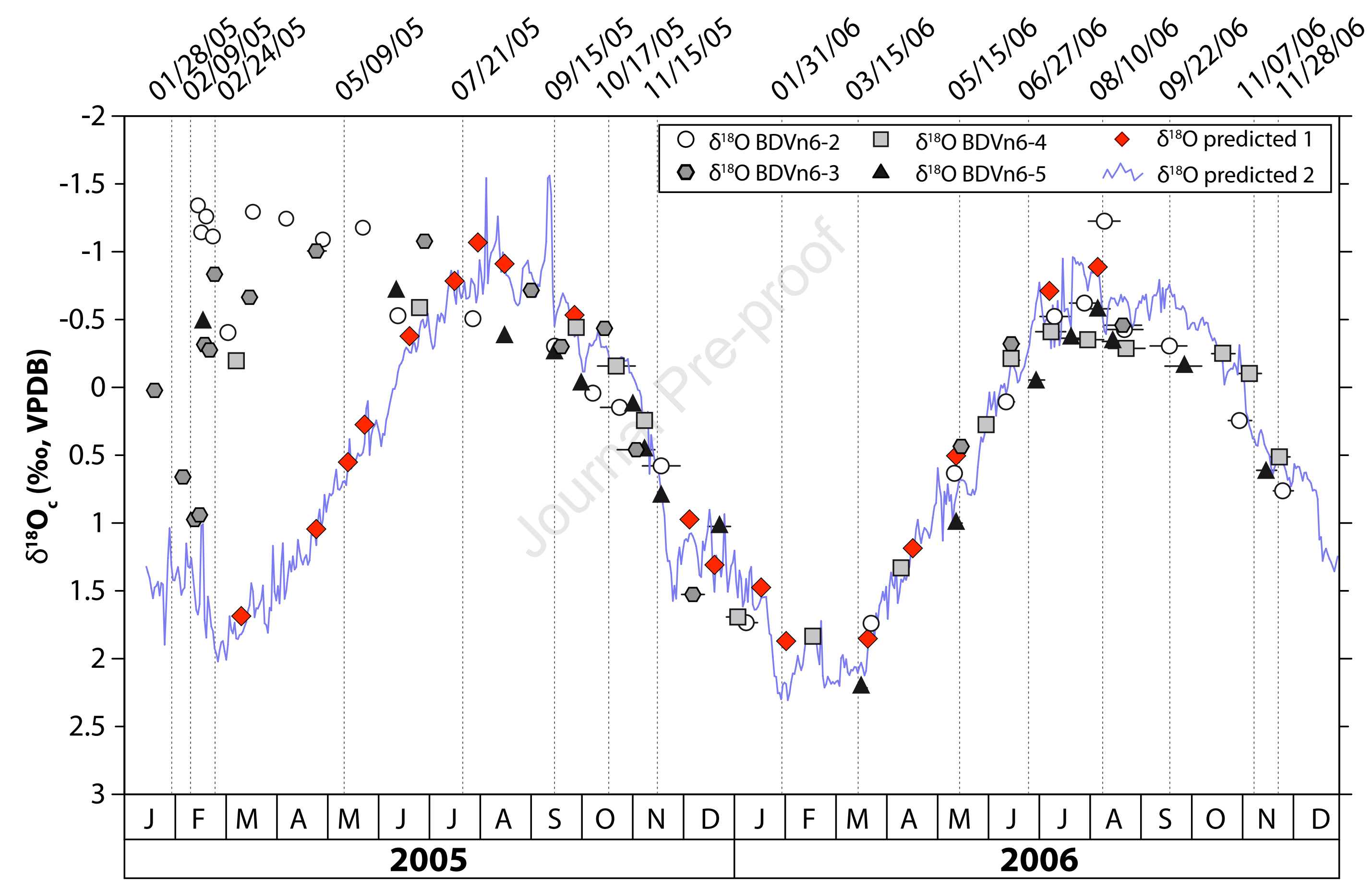




\section{Temperature $\left({ }^{\circ} \mathrm{C}\right)$}

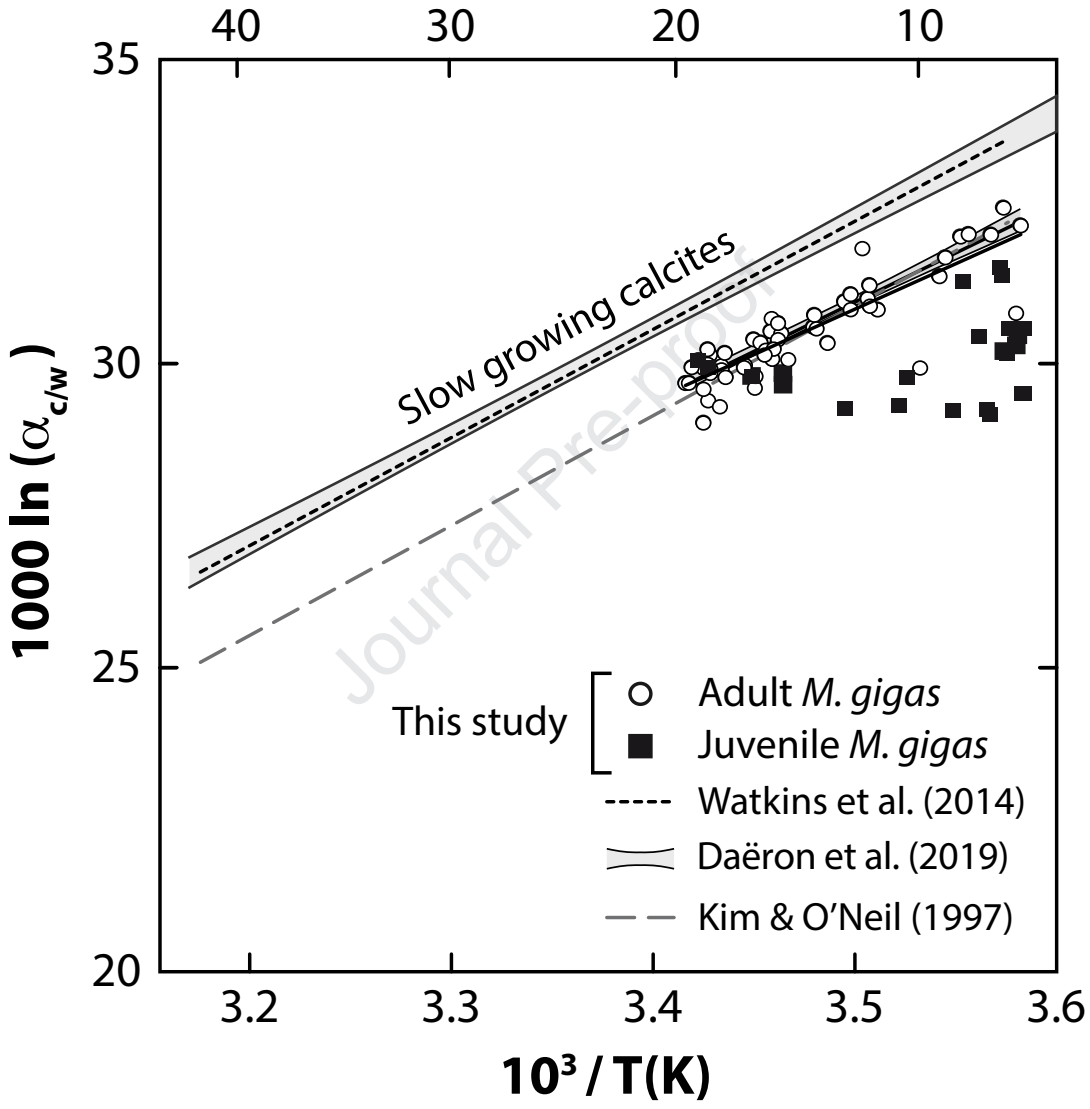




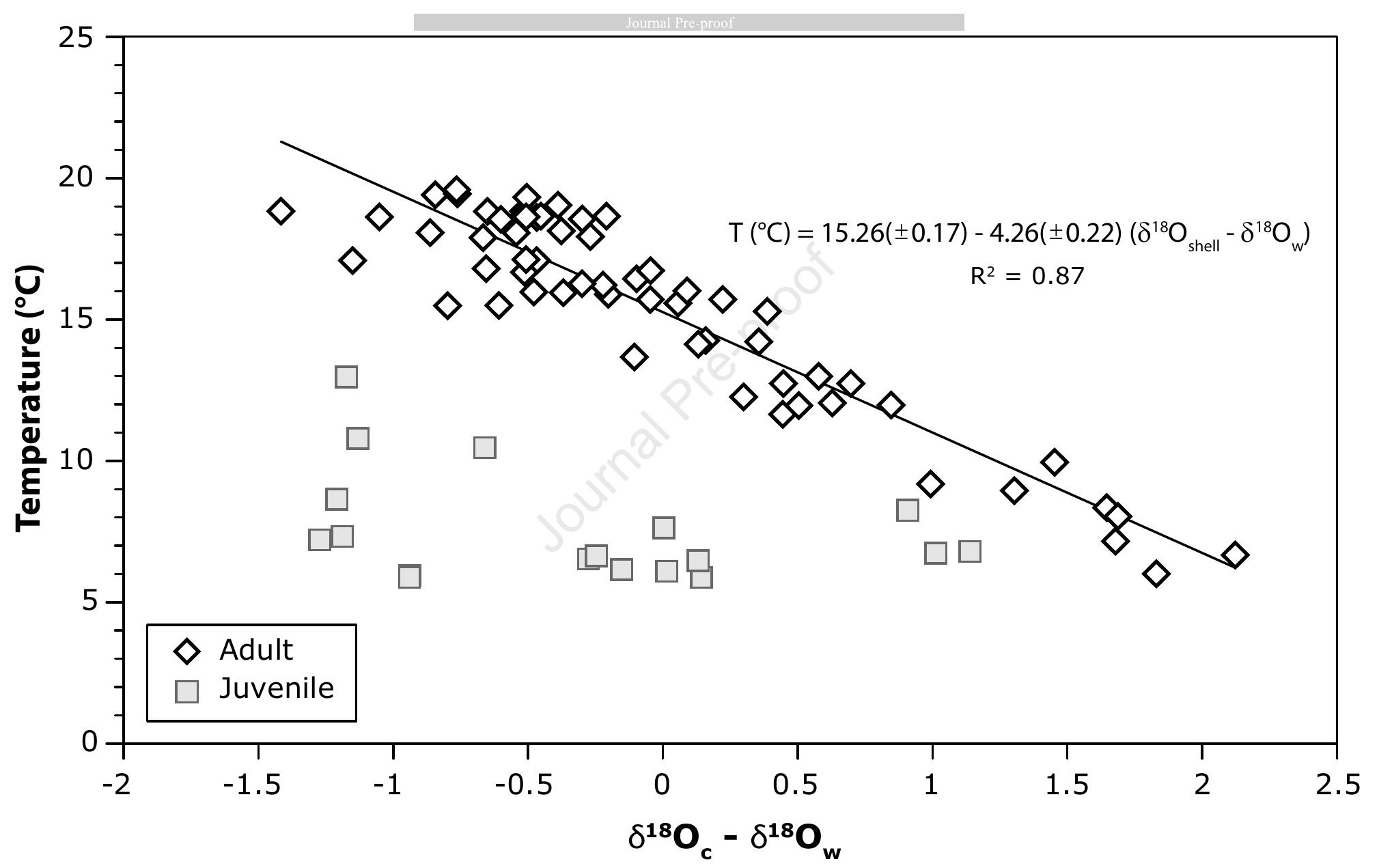




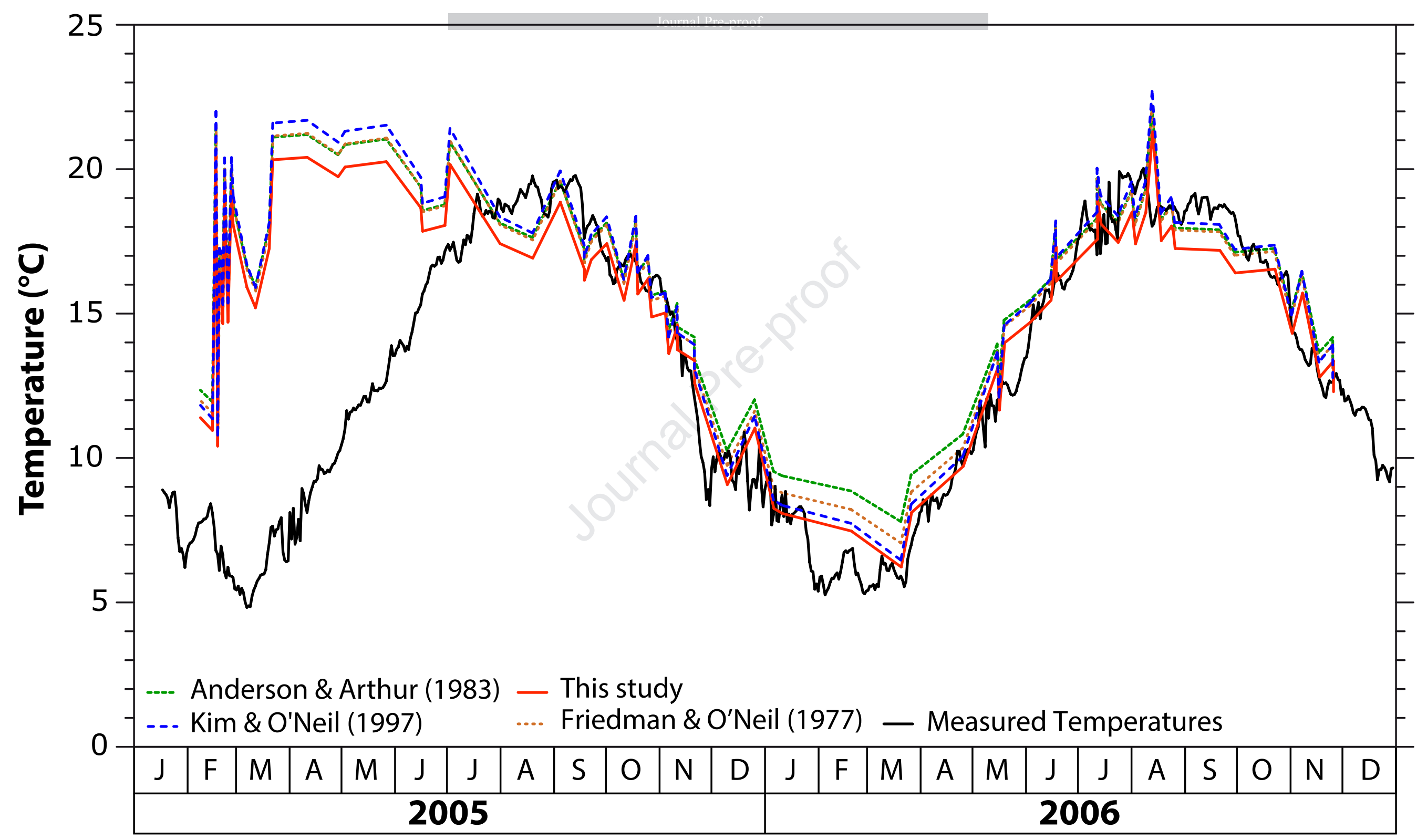




\section{Highlights}

- We analyze the $\delta^{18} \mathrm{O}$ composition of oyster shells of Normandy (France)

- An isotopic disequilibrium is identified during the juvenile portion of the shell

- Isotopic disequilibrium is related to kinetic effect due to fast growth rate

- Adult oysters mineralize their shells in equilibrium

- Juvenile portion of the shell should be avoided for paleoclimatic reconstructions 
Conflict of interest: The authors declare that they have no conflict of interest. 